\title{
The Study On Range Of Motion Of Hip And Knee In Prayer By Adult Muslim Males. A Preliminary Report
}

\author{
Ariff $\mathrm{MS}^{\mathrm{a}}$, Arshad $A A^{\mathrm{a}}$, Johari MHa, Rahimin Affandi $M A S^{\mathrm{a}}$, Fadzli $A S^{\mathrm{a}}$, Mai Ashikin $\mathrm{NT}^{\mathrm{b}}$, Che Anuar $\mathrm{CM}^{\mathrm{c}}$, Rosazra $\mathrm{R}^{\mathrm{c}}$, \\ Norhafiza $A R^{d}$ \\ ${ }^{a}$ Department of Orthopaedics, Traumatology and Rehabilitation, Kulliyyah (Faculty) of Medicine, International \\ Islamic University Malaysia (IIUM), Malaysia. \\ ${ }^{b}$ Department of Paediatrics, Kulliyyah (Faculty) of Medicine, International Islamic University Malaysia (IIUM), \\ Malaysia. \\ 'Department of Basic Medical Sciences, Kulliyyah (Faculty) of Pharmacy, International Islamic University \\ Malaysia (IIUM), Malaysia. \\ ${ }^{d}$ Department of Surgery, Kulliyyah (Faculty) of Medicine, International Islamic University Malaysia (IIUM), \\ Malaysia.
}

\begin{abstract}
Introduction: Praying represents a fundamental activity of daily living in Muslim community. Muslims need to adopt several postures that require deep flexion of the knee and hip to perform this daily obligation. This is a preliminary report of the study on hip and knee range of motion conducted to obtain normative passive and functional range of flexion data during Muslim prayers in both weight-bearing joints of normal Muslim adults. Methods: A cohort of Malay men aged between 20 to 30 years was recruited in this cross-sectional study. Passive range of motion and flexion angles of the joints in various postures during prayer were measured using a standard goniometer. The difference against existing normative range of motion database available and the influence of various factors were analysed. Factors analysed include body mass index and other anthropometric measurements. Results: Sixty participants recruited for the preliminary phase of this study. The mean (SD) of passive hip and knee flexions were higher compared to other existing normative range of motion database. A unit increase in body mass index will have 0.782 units lower of knee range of motion. The hip and knee flexion arc were from $74.1^{\circ}$ to $119.0^{\circ}$ and from $3.3^{\circ}$ to $119.7^{\circ}$ respectively. Conclusion: The range of motion involved for prayers was more for the knee but less for the hip as compared to the measured passive range of motion. Body mass index has a significant linear negative relationship with the passive range of motion of the knee, but not the hip.
\end{abstract}

KEYWORDS: hip articulation, knee articulation, Muslim anthropometry, Muslim prayer, range of motion.

\section{INTRODUCTION}

Evaluation of joint range of motion (ROM) is widely used in musculoskeletal research fields as well as assessment of therapeutic outcomes. Data on normal range ROM are used as reference value in disability assessments, orthopaedic implant development, and effectiveness of treatments. Normative data of joint ROM is of more value if evaluated in daily activities. An example of established data that is available and widely used are the satisfactory range of knee flexion

Corresponding author:

Dr. Mohd Ariff Sharifudin

Department of Orthopaedics, Traumatology and

Rehabilitation,

Kulliyyah (Faculty) of Medicine, International

Islamic University Malaysia,

Jalan Hospital, 25150 Kuantan, Pahang, Malaysia

Telephone: +60193352499

Fax: +6095144451

Email:ariffs@iium.edu.my/ mdariffs@hotmail. com required for various activities of daily living including degrees of flexion required for climbing up stairs, rising up from chair, and walking. ${ }^{1}$

But for Muslim populations, higher ROM is required as their religious and cultural activities demands greater flexion of the joints in the lower limbs. ${ }^{2}$ Among the important activities of daily living in Muslim populations is the act of prayer. A Muslim is expected to pray from the age of seven years and five times daily, resulting in a significant number of knee and hip flexion over a lifetime an estimate of 70 times a day. ${ }^{3}$ Muslim prayer, or "solah", involves standard physical motions such as standing, bowing, sitting, and prostration. It is crucial for every Muslim to be able to perform these various postures, which require significant amount of flexion of the lower limb joints to fulfil their religious responsibilities. These postures demand greater ROM as compared to their Western counterparts. ${ }^{4}$ However, there remains until today, a lack of information on hip and knee flexion angles related to different postures in Muslim prayers from an orthopaedic point of view. 
This study aims to determine the characteristics of hip and knee flexion during prayer by Muslims in the local population. We would like to determine the normal passive ROM for the hip and knee joints in healthy young Malay Muslim adults, and the flexion angles during different postures of prayer. Furthermore, we would like to determine the correlation between anthropometric measurements and body mass index (BMI) with the differences in hip and knee flexion angles. We hypothesized that the ROM of hip and knee of healthy young Malay Muslim adults in the local population are different compared to existing normative data of other populations.

\section{MATERIALS AND METHODS}

\section{Study Design and Sampling}

This research used an observational cross-sectional study design. This design focused on the measurements of hip and knee ROM during prayer by Muslims. The difference between measurements obtained and existing normative ROM database available, and the influence of various factors to the measurements formed the core matter of this study. The reference population comprised of adult Malay Muslims of Malaysian origin. The students and staffs from various faculties of the International Islamic University Malaysia (Kuantan Campus) are the source population recruited in this study. Participants were selected among adult Malaysian Malay males aged between 20 and 30 years with no history of generalized ligamentous laxity, as well as acquired or congenital affections or deformities of the spine, hips or knees. Those with history of previous surgeries of the lower limbs or spine, or any pathological conditions like neurological or systemic that can affect the musculoskeletal system such as knee, hip, ankle or lumbosacral joint pain, stiffness or deformity, were excluded from this study.

\section{Research Tools}

Seca (c) weight and height scales were used to measure participants' weight and height in centimetre $(\mathrm{cm})$ to the nearest $0.1 \mathrm{~cm}$. Limb lengths, abdominal and limb circumferences were measured using a flexible measuring tape graduated by $1 \mathrm{~mm}$. A standard, transparent goniometer was used to measure the ROM of hip and knee bilaterally according to the goniometry technique suggested by Norkin and White ${ }^{5}$ and adhering to a standard protocol. Three examiners (students under the supervision of an orthopaedic surgeon) were designated to measure the three groups of measurements, each for ROM of the hip, knee, or ROM of both joints during prayer. Three readings were taken for each measurement and averages calculated and recorded.

\section{Data Collection}

Data collection was commenced after approval by the IIUM Research Ethics Committee (IREC). Demographic data and anthropometric measurements were recorded in a data collection form. Physical examinations were conducted in a designated room to ensure the modesty of participants protected during the course of assessments. Age was recorded in years. Weight and height were measured twice and recorded in SI unit of kilogram $(\mathrm{kg})$ to the nearest $0.1 \mathrm{~kg}$ and centimetre $(\mathrm{cm})$ to the nearest $0.1 \mathrm{~cm}$, respectively. Participants only wore light clothing during measurement. Shoes were removed during weighing. Heels were placed closed together and participants were asked to look ahead horizontally. Body mass index (BMI) was calculated using the formula weight (in kilogram) divided by height (in meter square). It is categorized according to World Health Organization (WHO) BMI classification; normal (BMI of <24.9), overweight (BMI of between 25.0 and 29.9), and obese (BMI of >30.0). True length of both lower limbs was measured from the anterior superior iliac spine (ASIS) till the medial malleolus once confirming both limbs were positioned with a squared pelvis. Abdominal circumference was measured at the level of umbilicus. Limb circumference was measured separately for the thigh and calf of both limbs. Measurements were done at the level of $10 \mathrm{~cm}$ from the medial joint line to the thigh and calf respectively. All measurements of length were recorded in SI unit of $\mathrm{cm}$ to the nearest $0.1 \mathrm{~cm}$.

\section{Range of Motion Measurement Protocol}

As the focus of this research was to study the hip and knee flexion during prayer by Muslims, measurements were limited to the recording of passive flexion in the hip and knee joint (Figure 1), and ROM of both joints during postures of prayer. These postures include bowing, prostration and sitting. Prior to commencing the prayer movements, markers were placed on anatomical landmarks as reference points to facilitate goniometer placement and flexion angle measurement; tip of lateral malleolus, fibula head, lateral condyle of femur, greater trochanter of femur, and a point over iliac crest that crosses the lateral midline of pelvis. Measurements were recorded during three postures in prayer; bowing (ruku'), prostration (sujud), and sitting (jalsah). Similar technique of goniometer placement and recording of measurement during passive ROM assessment were used to record both joint flexion angles during prayer movements. As the study focused on flexion angles during prayer movements, both joints position during standing were taken as $0^{\circ}$.

\section{a. Bowing (Ruku')}

Participants were asked to perform their normal postures of bowing by partial forward flexion of the spine and hips while keeping both knees straight or hyperextended. Both hand were placed on the knees. The flexion angles of the hips and knees were measured at the end of this movement (Figure 2).

\section{b. Prostration (Sujud)}

Prostration was achieved by kneeling on the praying mat then placing the forehead and part of the nose on the mat. Both hands were placed on the mat, horizontally parallel with the head. Measurements were also recorded at the end of this movement (Figure 3). 


\section{c. Sitting (Jalsah)}

Subjects sat on the prayer mat, supported by fully flexed knees and flexed hips in an upright torso. The flexion angles of the hips and knees were measured and recorded at the end of this posture (Figure 4).

\section{Statistical Analysis}

All the data entry and analysis were performed using will be done using the Social Science and Statistical Packaged (SPSS) version 22. Numerical data were expressed using mean (SD). Categorical data were expressed using numbers and percentages. Descriptive analysis for mean, standard deviation (SD), range, and percentage was used to analyze the age, height, weight, BMI, dominant side, limb length, abdominal and limb circumferences. Similar descriptive analysis was used for the passive and prayer ROM assessment. Simple linear regression and multiple linear regressions were used to analyse the anthropometric factors influencing the ROM of the hip and knee joints.
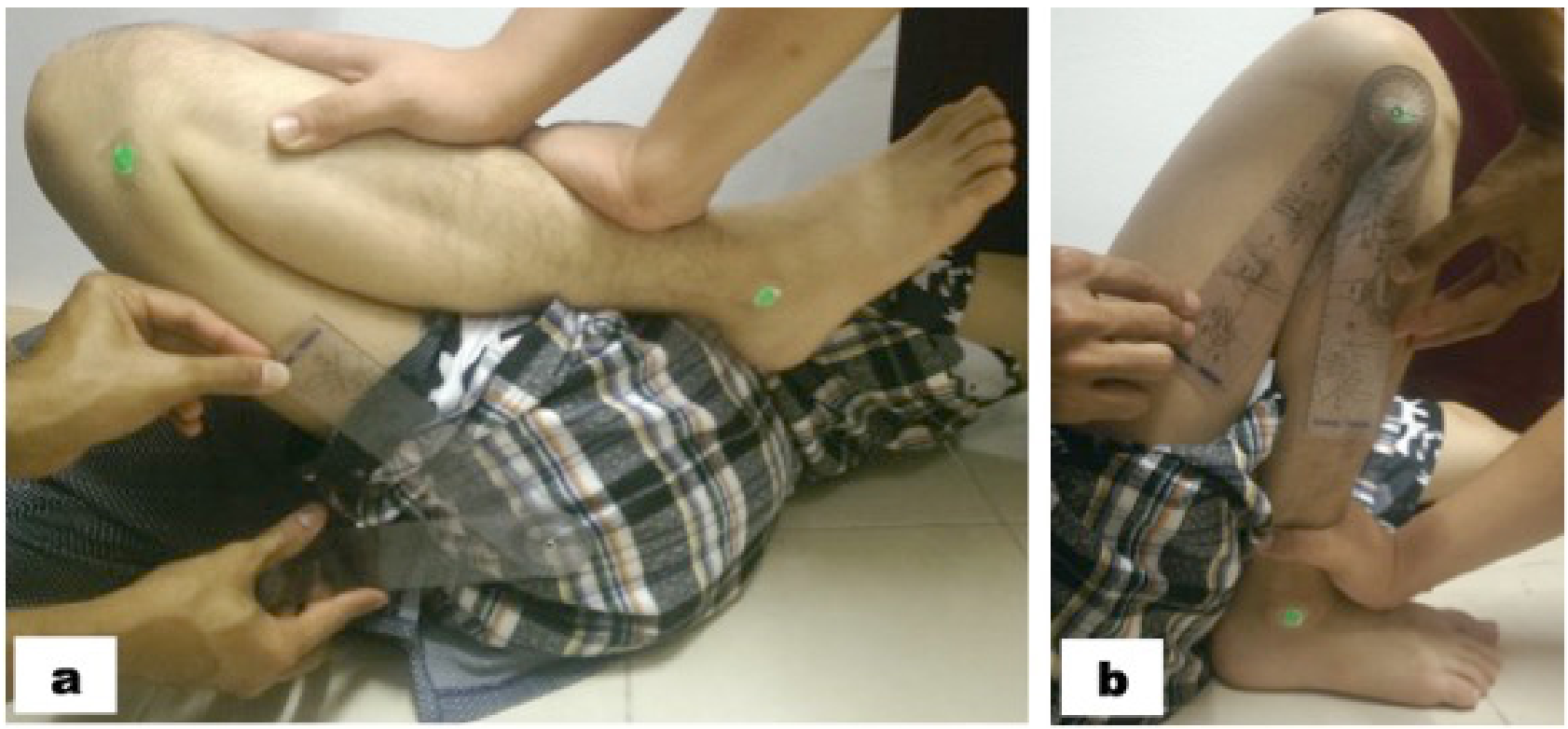

Figure 1. Passive flexion of the (a) hip and (b) knee measurement.
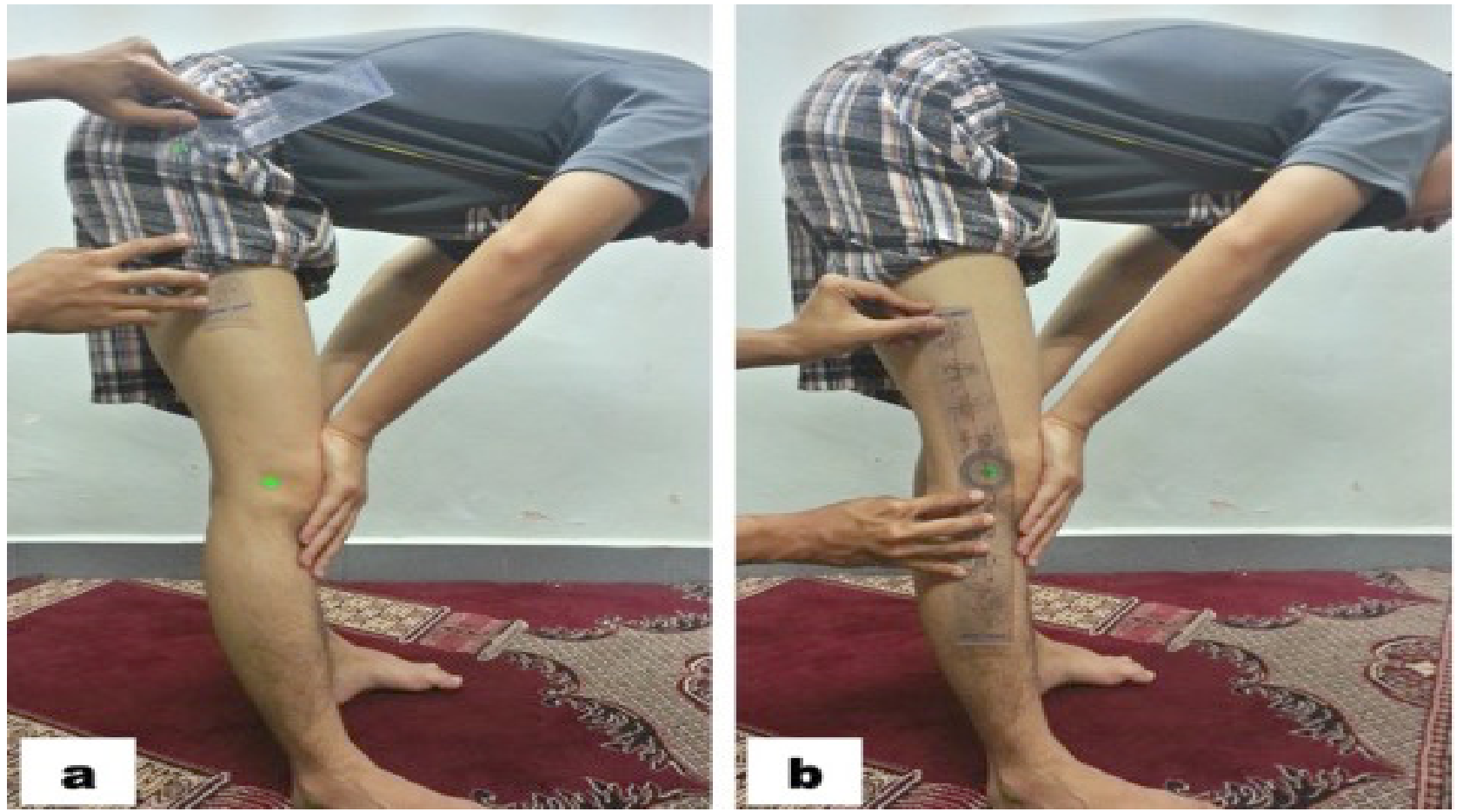

Figure 2. Bowing posture and measurement of the (a) hip and (b) knee joints at the end of the posture. 


\section{IMJM}
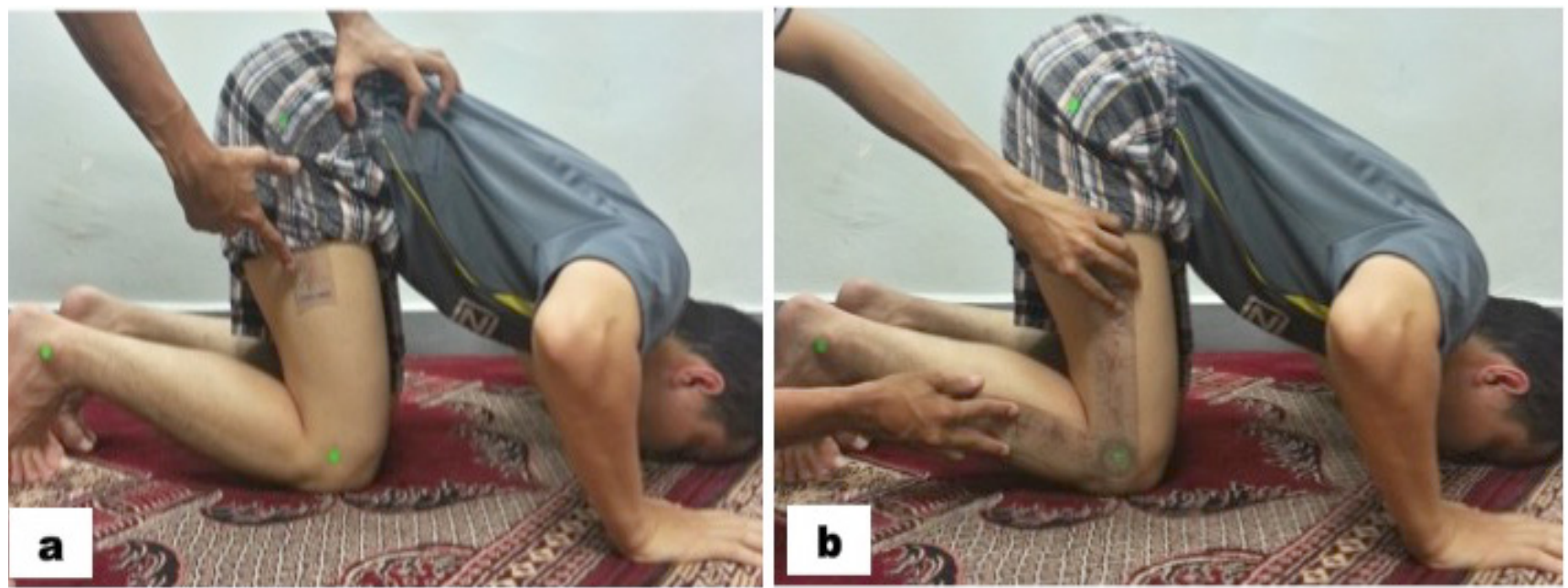

Figure 3. Prostration and measurement of the (a) hip and (b) knee joints at the end of the posture.
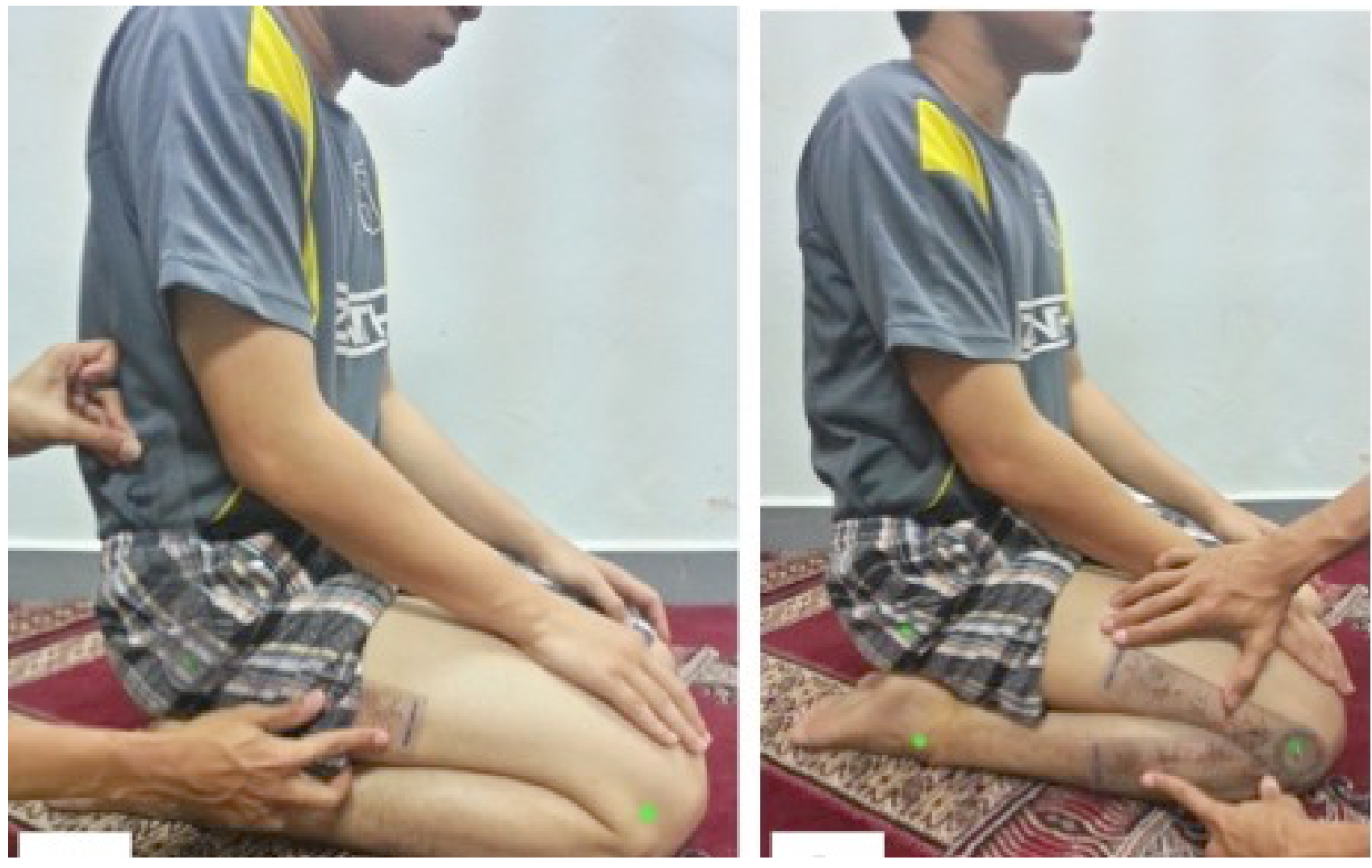

Figure 4. Sitting and measurement of the (a) hip and (b) knee joints at the end of the posture.

\section{RESULTS}

A total of 60 healthy, young Malay Muslim adults were recruited for the preliminary phase of the study. The demographic characteristics of the participants are shown in Table I. The mean (SD) age of the participants was 22.6 years old. Majority of our participants, $70.0 \%(n=42)$, had normal BMI. $13.3 \%(n=8)$ were overweight, and a large number of them, $16.7 \%$ ( $n$ = 10) were categorized as obese based on their BMI. The mean BMI for this group of individuals was 21.5. Majority of them were found to be right-handed $(98.3 \%)$, while only $1.7 \%$ of them were left-handed. 
Table I. Descriptive statistics for knee and hip flexion during prayers in normal individuals

\begin{tabular}{|c|c|c|c|c|}
\hline \multicolumn{2}{|l|}{ Variable } & \multicolumn{2}{|l|}{ n (\%) } & Mean (SD) \\
\hline \multicolumn{2}{|l|}{ Age } & $60(100)$ & \multicolumn{2}{|c|}{$22.6(1.4)$} \\
\hline \multicolumn{2}{|c|}{ Body Mass Index (BMI) } & & \\
\hline \multicolumn{2}{|c|}{$<23$} & \multicolumn{3}{|l|}{$42(70.0)$} \\
\hline \multicolumn{2}{|l|}{$23-24.9$} & \multicolumn{3}{|l|}{$8(13.3)$} \\
\hline \multicolumn{2}{|l|}{$>25$} & \multicolumn{3}{|l|}{$10(16.7)$} \\
\hline \multicolumn{5}{|l|}{ Dominant side } \\
\hline \multicolumn{2}{|l|}{ Left } & \multicolumn{3}{|l|}{$1(1.7)$} \\
\hline \multicolumn{2}{|l|}{ Right } & \multicolumn{3}{|l|}{$59(98.3)$} \\
\hline \multicolumn{5}{|l|}{ True length } \\
\hline \multirow{2}{*}{\multicolumn{2}{|c|}{$\begin{array}{l}\text { Left } \\
\text { Right }\end{array}$}} & \multicolumn{3}{|c|}{$89.0(4.7)$} \\
\hline & & \multicolumn{3}{|c|}{$89.0(4.8)$} \\
\hline \multicolumn{2}{|c|}{ Abdominal circumference } & \multicolumn{3}{|c|}{$76.5(8.3)$} \\
\hline \multicolumn{5}{|c|}{ Thigh circumference } \\
\hline \multirow{2}{*}{\multicolumn{2}{|c|}{$\begin{array}{l}\text { Left } \\
\text { Right }\end{array}$}} & & & 5.1) \\
\hline & & & & 5.2) \\
\hline Calf circumference & & & & \\
\hline Left & & & & $3.2)$ \\
\hline Right & & & & $3.3)$ \\
\hline Range of motion & & Minimum & Maximum & Mean (SD) \\
\hline Hip & & & & \\
\hline Passive & Left & 126.7 & 158.3 & $141.3(7.0)$ \\
\hline & Right & 123.3 & 156.7 & $141.3(7.7)$ \\
\hline Prayer & & & & \\
\hline Bowing & Left & 53.3 & 86.7 & $74.3(6.6)$ \\
\hline & Right & 60.0 & 85.0 & $74.1(6.2)$ \\
\hline Prostration & Left & 95.0 & 140.0 & $119.0(9.4)$ \\
\hline & Right & 91.7 & 138.3 & $118.1(9.1)$ \\
\hline Sitting & Left & 65.0 & 88.3 & $77.7(5.1)$ \\
\hline & Right & 65.0 & 90.0 & $77.3(4.6)$ \\
\hline Knee & & & & \\
\hline Passive & Left & 140.0 & 160.0 & $152.2(4.7)$ \\
\hline & Right & 140.0 & 161.7 & $152.9(4.7)$ \\
\hline Prayer & & & & \\
\hline Bowing & Left & -5.0 & 13.3 & $3.3(4.1)$ \\
\hline & Right & -5.0 & 15.0 & $3.6(4.0)$ \\
\hline Prostration & Left & 101.7 & 130.0 & $116.7(7.1)$ \\
\hline & Right & 101.7 & 130.0 & $115.8(6.4)$ \\
\hline Sitting & Left & 140.0 & 165.0 & $153.3(5.6)$ \\
\hline & Right & 141.7 & 165.0 & $153.8(6.0)$ \\
\hline
\end{tabular}


True limb length measurement for the right and left lower limbs showed that the mean was $89.0 \mathrm{~cm}$ with SD 4.8 and 4.7 respectively. The abdominal circumference measurement for our study sample had a mean of $76.5 \mathrm{~cm}$. The mean for limb circumference for the thigh and calf of the respective sides was $50.5 \mathrm{~cm}$ for the right thigh, $50.9 \mathrm{~cm}$ for the left thigh, $31.7 \mathrm{~cm}$ for the right calf, and $31.9 \mathrm{~cm}$ for the left calf.

There was a significant difference between the means of the left and right thigh circumference, while there was no significant difference for the calf circumference (Table II). The mean circumference between the left and right thigh was significantly different $(p=0.002)$. It was observed that the mean left thigh difference was lower compared to mean right thigh circumference. There was 95\% confidence that the mean difference of thigh circumference between left and right will be between 0.16 and 0.67 . The mean difference between left and right calf circumference was not statistically significant $(p=0.056,95 \% \mathrm{Cl} 0.00,0.37)$. Confidence interval does not include the null value of 0 .

Table II. Mean difference between left and right calf and thigh circumferences, and left and right prayer ROM for the hip and knee joints.

\begin{tabular}{lccccc}
\hline Variables & $\begin{array}{c}\text { Left mean } \\
(\mathrm{SD})\end{array}$ & $\begin{array}{c}\text { Right mean } \\
(\mathrm{SD})\end{array}$ & $\begin{array}{c}\text { Mean Difference } \\
(95 \% \mathrm{Cl})\end{array}$ & t-statistics (df) & $\mathrm{p} \mathrm{valu \textrm {a } ^ { \mathrm { a } }}$ \\
\hline Calf circumference & $31.9(3.2)$ & $31.7(3.3)$ & $0.2(0.00,0.37)$ & $1.949(59)$ & 0.056 \\
Thigh circumference & $50.9(5.1)$ & $50.5(5.2)$ & $-0.4(0.16,0.67)$ & $3.270(59)$ & 0.002 \\
ROM hip & $141.3(7.0)$ & $141.3(7.7)$ & $-0.1(-1.42,1.31)$ & $-0.082(59)$ & 0.935 \\
ROM knee & $152.2(4.7)$ & $152.9(4.7)$ & $-0.7(-1.62,0.18)$ & $-1.609(59)$ & 0.113 \\
\hline
\end{tabular}

a Paired t-test

The mean, maximum and minimum ROM for passive and during the prayers are presented in Table III, which are given in degrees. The mean passive flexions of both right and left hips were $141.3^{\circ}$. However, the mean passive flexion for the left knee was slightly less $\left(152.2^{\circ}\right)$ than the contralateral knee $\left(152.9^{\circ}\right)$.

For the hip joint, the mean ROM involved for prayers were from $74.3^{\circ}$ (left hip) and $74.1^{\circ}$ (right hip) while bowing to $119.0^{\circ}$ (left hip) and $118.1^{\circ}$ (right hip) while prostration. The mean ROM involved in the knee joint during prayers were from $3.3^{\circ}$ (left knee) and $3.6^{\circ}$ (right knee) while bowing, to $153.3^{\circ}$ (left knee) and $153.8^{\circ}$ (right knee) while sitting. Thus, the maximum flexion was achieved while prostration in the hip, and while sitting in the knee joint.

In this study, there was not any significant difference between hip and knee passive ROM between the left and right side $(p=0.935$ and $p=0.113$, respectively)
(Table II). The difference between the mean of passive ROM and the prayer position recording the mean maximum flexion for respective joints were calculated (Table III).

The hip joint was in maximum flexion during the prostration posture, which was much lower than the measured passive ROM. The knee joint was noted to have attained maximum flexion during the sitting posture, which was higher compared to the passive knee ROM. The mean ROM between left hip during prostration and normative ROM was significantly different $(p<0.001)$. It was observed that the ROM of the left hip was lower during prostration and were 95\% confident that the mean difference will be between -25.1 and -19.4 (Table III). The mean ROM of left knee during sitting posture was higher compared to the normative ROM. However, the difference between the two was not statistically significant $(p=0.098)$ (Table III). 
Table III. The comparison between mean of hip ROM during prostration and hip passive movement, and between mean of knee ROM during sitting and knee passive movement.

\begin{tabular}{lcccccc}
\hline Variables & & $\begin{array}{c}\text { Prayer ROM } \\
\text { mean (SD) }\end{array}$ & $\begin{array}{c}\text { Passive ROM } \\
\text { mean (SD) }\end{array}$ & $\begin{array}{c}\text { Mean difference } \\
(95 \% \mathrm{Cl})\end{array}$ & $\begin{array}{c}\text { t-statistics } \\
(\mathrm{df})\end{array}$ & p valuea \\
\hline \multirow{2}{*}{ Hip ROM } & Left & $119.0(9.4)$ & $141.3(7.0)$ & $-22.3(-25.1,-19.4)$ & $-15.585(59)$ & $<0.001$ \\
& Right & $118.1(9.1)$ & $141.3(7.7)$ & $-23.2(-26.3,-20.2)$ & $-15.223(59)$ & $<0.001$ \\
\multirow{2}{*}{ Knee ROM } & Left & $153.3(5.6)$ & $152.2(4.7)$ & $1.1(-0.20,2.31)$ & $1.682(59)$ & 0.098 \\
& Right & $153.8(6.0)$ & $152.9(4.7)$ & $0.8(-0.50,2.16)$ & $1.254(59)$ & 0.215 \\
\hline
\end{tabular}

a Paired t-test

Associated factor analysis for the influence of ROM was performed using simple and multiple linear progression models. Age did not have any significant influence on the ROM studied for both the hip and the knee joints (p-value of 0.426 and 0.728 , respectively) (Table IV). However, the other factors had significant influence on the knee joints $(p<0.05)$. None of them significantly influence the hip joint ROM in prayers (Table IV). The results from multiple linear regression analysis show that there is a significant linear negative relationship between $\mathrm{BMI}$ and ROM of knee. Those with 1 unit increase in BMI will have 0.782 units lower ROM of knee (adjusted $\mathrm{b}=-0.782,95 \% \mathrm{Cl}-1.154,-0.409$, $\mathrm{p}<0.05$ ) (Table IV).

Table IV. Associated factors of ROM of the hip and knee joints during Muslim prayer.

\begin{tabular}{|c|c|c|c|c|c|c|}
\hline \multirow[t]{2}{*}{ Variables } & \multicolumn{2}{|c|}{ Simple Linear Regression } & \multicolumn{4}{|c|}{ Multiple Regression } \\
\hline & $b^{a}(95 \% C l)$ & t-stat & $\mathrm{p}$ value & $\mathrm{b}^{\mathrm{b}}(95 \% \mathrm{Cl})$ & t-stat & $\mathrm{p}$ value \\
\hline \multicolumn{7}{|l|}{ Hip } \\
\hline Age & $\begin{array}{l}-0.666 \\
(-2.326,0.995)\end{array}$ & -0.803 & 0.426 & - & - & - \\
\hline BMI & $\begin{array}{l}0.298 \\
(-0.481,1.007)\end{array}$ & 0.765 & 0.447 & - & - & - \\
\hline $\begin{array}{l}\text { Abdominal } \\
\text { Circumference }\end{array}$ & $\begin{array}{l}0.091 \\
(-0.189,0.371)\end{array}$ & 0.650 & 0.518 & - & - & - \\
\hline $\begin{array}{l}\text { Thigh } \\
\text { Circumference }\end{array}$ & $\begin{array}{l}0.090 \\
(-0.367,0.546)\end{array}$ & 0.392 & 0.696 & - & - & - \\
\hline $\begin{array}{l}\text { Calf } \\
\text { Circumference }\end{array}$ & $\begin{array}{l}0.443 \\
(-0.276,1.162)\end{array}$ & 1.234 & 0.222 & - & - & - \\
\hline \multicolumn{7}{|l|}{ Knee } \\
\hline Age & $\begin{array}{l}-0.179 \\
(-1.085,0.728)\end{array}$ & -0.395 & 0.728 & - & - & - \\
\hline $\mathrm{BMI}$ & $\begin{array}{l}-0.782 \\
(-1.154,-0.409)\end{array}$ & -4.198 & $<0.05$ & $\begin{array}{c}-0.782 \\
(-1.154,-0.409)\end{array}$ & -4.198 & $<0.05$ \\
\hline $\begin{array}{l}\text { Abdominal } \\
\text { Circumference }\end{array}$ & $\begin{array}{l}-0.276 \\
(-0.411,-0.142)\end{array}$ & -4.116 & $<0.05$ & - & - & - \\
\hline $\begin{array}{l}\text { Thigh } \\
\text { Circumference }\end{array}$ & $\begin{array}{l}-0.381 \\
(-0.609,-0.154)\end{array}$ & -3.355 & $<0.05$ & - & - & - \\
\hline $\begin{array}{l}\text { Calf } \\
\text { Circumference }\end{array}$ & $\begin{array}{l}-0.582 \\
(-0.947,-0.217)\end{array}$ & -3.192 & $<0.05$ & - & - & - \\
\hline
\end{tabular}

\footnotetext{
a Crude regression coefficient, bAdjusted regression coefficient, $R 2=0.220$ Forward multiple linear regression method applied, Model assumption are fulfilled, There was no need to check for interaction, as only 1 variable was significant in multivariable analysis. No multicollinearity detected
} 


\section{DISCUSSION}

Age was reported to influence ROM with general decline in flexibility of joints with advancing age. The ROM fluctuation was notable in the infant and aged persons, and the degrees of variations were joint specific. The mean age of the current cohort was 22.6 years. Other age groups were not included in this study to eliminate the influence of age factors, which could affect ROM. Simple linear regression for variable exploration revealed that age did not have any significant correlation for both hip and knee motions.

A significant difference in thigh circumference was noted. There was no significant difference in the calf circumference. The mean circumference for the left thigh (less dominant side) was higher than the right side. This finding in our current study is not in accordance with the earlier reports. Kearns et al. attributed the discrepancy of measurement between dominant and non-dominant limb to the preferential use of one limb over another resulting in larger muscle in the dominant limb. ${ }^{11}$ In another study, calf circumference was reported to be marginally significant higher $(p=0.039)$ in the dominant leg of middle-aged individuals in Canada. ${ }^{12}$ However, in a study of 59 healthy children aged between 8 and 10 years reported no difference in calf circumference between dominant and nondominant lower extremity. ${ }^{13}$ Furthermore, Moseley et al. reported that though variations between the dominant and non-dominant leg do occurs, they were not clinically or functionally significant. ${ }^{14}$

There was no significant difference of ROM between the right and left limbs observed in this study. Macedo and Magee reported smaller ROM in the joints of the dominant upper and lower limbs, but the differences were small and not clinically significant. Hence, the authors advocated the use of the contralateral joints as indicator of normal ROM.15 Our findings of no significant difference in ROM between the dominant and non-dominant lower limb was also in agreement with other previous studies. ${ }^{16,17}$

The mean BMI for the participants in this study was 21.5. This is lower than the overall mean BMI of Malaysian adults as reported in a National Nutritional assessment conducted in $2002 .{ }^{18} \mathrm{~A}$ rational explanation for this difference is participants of this study comprised of only young Malays with narrow age limit. The current study demonstrates a negative correlation between BMI and passive ROM measured for the knee joint. However, this correlation was not observed for the ROM of the hip joint. In an analysis of data from San Antonio longitudinal study of aging in 687 subjects (aged between 65 and 79 years) Escalante et al. concluded that increasing BMI reduced flexion range in the hip and knee significantly. ${ }^{19}$ Similar conclusion was made in previous studies on correlation between BMI and ROM of lumbar and hip joints. ${ }^{20,21}$ Other normative ROM studies did not analyze the effect of BMI.6,9,16,22
Many nutritional and anthropometric studies have extensively analyzed the clinical significance of lower limb circumference. However, there is still lack of adequate evidence on the importance of the relationship between ROM of joints of lower limb and limb circumference. This is reflected by the limited published data in the literature on the subject matter. In a study conducted in Canada, Zelle et al. concluded that thigh and calf circumference affects the flexion angle of knee joint, which is influenced by the thighcalf contact. ${ }^{23}$ Gajdosik and Bohannon in their review have addressed the limitation of goniometer as compared to radiographic analysis in measuring ROM, which include the presence of excessive muscle bulk. However, this limitation is still accepted clinically. ${ }^{24}$ In our preliminary data, a comparison of the calf circumference showed no significant difference.

However, a significant difference of thigh circumference between the left and right limb was. After controlling all significant and biologically plausible variables by using simple and multiple linear regression analyses, the thigh and calf circumference did not show any significant influence on the passive ROM of both hip and knee joints. Similar findings were observed when analysing the influence of abdominal circumference on the passive ROM of hip and knee joints. Our literature search did not show any previous studies with regard to the influence of abdominal circumference on the ROM of lower limb joints.

The mean of passive ROM obtained in this study was $141.3^{\circ}$ for both left and right hip joints. As for the knee joints, the mean of passive ROM obtained was $152.2^{\circ}$ and $152.9^{\circ}$ for left and right side, respectively. Higher passive ROM for both hip and knee joints were observed compared to some existing Western normative data ${ }^{6,16}$ and to a Japanese normative data.25 The obtained values for ROM of knee joint in the current study were also higher compared to the average knee joint ROM measured in school going boys of Amritsar, Punjab, in which the average knee joint ROM was $142^{\circ} .{ }^{26}$ When compared with the reference range of hip and knee ROM provided by the American Academy of Orthopaedic Surgeons (AAOS), our results varied more by $21^{\circ}$ for the hip joint, and $17^{\circ}$ for the knee joint. ${ }^{5}$

The passive ROM values of subjects aged between 25 and 74 years old by Roach and Miles 9 was less by $20^{\circ}$ for both hip and knee joints compared to the current study. Our results were similar for the hip, but varied more for the knee joint by $19^{\circ}$ when compared to a normative study on Iranians. ${ }^{27}$ In another study on 50 Saudi Arabian men of 30 to 40 years of age, the results were similar for the knee joint but were lesser by $11^{\circ}$ for the hip joint. ${ }^{16}$ Thus, the values observed based on our preliminary data showed differences of $10^{\circ}$ to $20^{\circ}$ compared to other existing normative ROM studies. This difference can be attributed to the various methodologies employed for joint ROM measurement. Nevertheless, this cannot dismiss the role of cultural and geographical influence on ROM of the hip and 
knee joints. Formulating ROM normative data for local population reference is imperative and essential.

Apart from evaluating the normal passive ROM of hip and knee joint of participants, this study was conducted to determine the characteristics of hip and knee joint functional flexion in male Malay young adults while praying. The inclusion and exclusion criteria limited age bias, and removed race and gender bias as well. The measurement bias was reduced by strictly adhering to a standard protocol by a single examiner for each measurement performed. With these precautions, a more accurate and reliable results hoped to be obtained. As the participants perform prayer postures, the hip and knee move into varying degree of flexion. The postures adopted in sequence; standing, bowing, prostration, then sitting. The standing posture was taken as the starting or neutral position with $0^{\circ}$ of flexion for both joints. From our observation, maximum flexion occurred during prostration for the hip, and during sitting for the knee. During bowing, the flexion angle was the smallest for both joints, especially the knee joint. The minimum and maximum hip joint flexion angle range was from $53^{\circ}$ to $140^{\circ}$ with the means degree of $74.1^{\circ}$ to $119.0^{\circ}$. The range obtained was much smaller compared to the measured passive ROM (Table III).

The arc of movement for the knee joint was from $-5^{\circ}$ to $165^{\circ}$ with the mean of $3.3^{\circ}$ to $153.8^{\circ}$. The result of a radiographic study of deep knee flexion in prayer positions of five healthy Saudi Arabian men identified flexion angles between $150^{\circ}$ and $165^{\circ}$ with the mean degree of $157.3^{\circ},{ }^{2}$ comparable to the values recorded in the current study. However, the knee flexion during the sitting posture is not comparable to the passive ROM obtained in this study and the sitting posture in the study done in Sapporo, Japan. ${ }^{28}$ This implies that the available normative data on passive knee flexion does not represent the functional high knee flexion attained during prayers.

This discrepancy would be best explained by comparing the full flexion of the knee achieved during sitting posture in prayer and full flexion in passive ROM of the knee joint. Passive range of motion is measured only in sagittal plane, while sitting posture in prayer involves other motions such as rotation of the knee, as well as synchronization of other joints, particularly the ankle joint. This will align the calf and the thigh in such a way that they are less obstructed by the muscle bulk, thus producing a higher angle of flexion. This complex movement was demonstrated in previous kinematics studies. ${ }^{29,30}$ With reference to the kinematic studies, it is implied if revision of arthroplasty implants could offer lesser ROM but nearing to the exact normative flexion, a patient might still able to attain the sitting posture with certain degree of self-adjustment to the hip and ankle joints.

\section{Limitations}

In this preliminary report, the age of the participants was limited with the intention to reduce aged biased data. However, this selection of cohort does not represent the older individuals, the expected candidates of arthroplasty surgery. The data obtained was not aimed to extrapolate to older subjects but to serve as a normative, local adult database and preliminary data on flexion during prayers. In order to make the correlation of studied variables more considerable, we decided to remove gender bias to further reduce confounding factors. On the other hand, valuable data from the fairer gender is lacking to generate a comprehensive normative database. Keeping in mind that this report is just to present preliminary data from a study with a larger sample size, gender factor will definitely be included.

As stated by Rothstein et al., the reliability of goniometry is at par with more expensive devices. ${ }^{31}$ The evaluation of ROM was strictly according to the standard technique of measurements as suggested in a review on the goniometry validity and reliability. ${ }^{24}$ A standardized procedure is a helpful leverage for the examiner's relative inexperience by which errors can be at least minimized if is not prevented. Although above steps are taken to ensure reliability, the same concurrence cannot be ensured to validity. Incorrect alignment of goniometer, and misidentification of landmarks are among the sources of error in measurement. ${ }^{32}$ As their study was concerning the elbow motion, the chances of the errors to occur are higher in the lower limbs. This might be the explanation for differences of the reading when comparison is being made. Measuring passive movements are also more prone to reliability error, ${ }^{24}$ but we allocated one dedicated assistant for each examiner to assist in joint stabilization for measurements in passive movements.

Research in this subject will provide a reference on the flexion of knee and hip joints that is required for a Muslim to perform the daily prayers. Data obtained can be used as foundation for researches in designing and developing 'ibadah-friendly' (compatible to the needs of Muslims to perform their religious obligations) orthopaedic devices, particularly in arthroplasty, as well as standard therapeutic and rehabilitative goals. An ideal arthroplasty implant for Muslims should be able to alleviate pain as well as providing necessary range of motion for prayers. This will definitely have an enhanced impact in Muslim communities. Defining the range of motion of knee and hip during prayers will satisfy the basic demands of Muslim patients undergoing arthroplasty surgery. Based on this study, the current available joint replacement device needs the range required to conduct Muslim prayers adequately for the hip joint. However, the available knee implant device does not yet allow Muslim individuals to satisfy their daily act of prayer.

\section{CONCLUSION}

This report represents the preliminary data of a larger study with larger sample size and inclusion of both genders. However, a wider range of age groups is necessary in order to understand the range of flexion in 
local aged population. The research methodology used is reproducible but comparative studies are needed to assess the reliability and validity of its use in general populations.

\section{ACKOWLEDGEMENT}

An abstract of this report was presented at the International Conference on Developing Synergies Between Islam and Science \& Technology for mankind's Benefit on 2nd of October 2014, organized by the International Institute of Advanced Islamic Studies (IAIS) Malaysia.

\section{REFERENCES}

1. Laubenthal KN, Smidt GL, Kettelkamp DB. A quantitative analysis of knee motion during activities of daily living. Phys Ther 1972;52:34-43.

2. Hefzy MS, Kelly BP, Cooke TD. Kinematics of the knee joint in deep flexion. A radiographic assessment. Med Eng Phys 1998; 20:302-7.

3. Gibson T, Hameed K, Sultana S, Fatima Z, Syed A. Knee pain amongst the poor and affulent in Pakistan. Brit J Rheumatol 1996; 35:146-9.

4. Mullholland SJ, Wyss UP. Activities of daily living in non-Western cultures. Range of motion requirements for hip and knee joint implants. Int J Rehabil Res 2001; 24:191-8.

5. Norkin CC, White JD. Measurement of a joint motion: a guide to goniometry. 3rd ed. F.A. Davis Company, Philadelphia, 2003.

6. Boone DC, Azen SP. Normal range of motion of joints in male subjects. J Bone Joint Surg 1979; 61:756-9.

7. Bell RD, Hoshizaki TB. Relationships of age and sex with range of motion of seventeen joint actions in humans. Can J Appl Sport Sci 1981; 6:202-6.

8. Svenningsen S, Terjesen T, Auflem M, Berg V. Hip motion related to age and sex. Acta Orthop Scand 1989; 60:97-100.

9. Roach KE, Miles TP. Normal hip and knee active range of motion: the relationship to age. Phys Ther 1991; 71:656-65.

10. Steinberg N, Hershkovitz I, Peleg S, et al. Range of joint movement in female dancers and nondancers aged 8 to 16 years: anatomical and clinical implications. Am J Sports Med 2006; 34:814-23.

11. Kearns CF, Isokawa M, Abe T. Architectural characteristics of dominant leg muscles in junior soccer players. Eur J Appl Physiol 2001; 85:24043.

12. Valderrabano V, Nigg BM, Hintermann B, et al. Muscular lower leg asymmetry in middle-aged people. Foot Ankle Int 2007; 28:242-9.

13. Beenakker EA, de Vries J, Fock JM, et al. Quantitative assessment of calf circumference in Duchenne muscular dystrophy patients. Neuromuscular Disord 2002; 12:639-42.

14. Moseley AM, Crosbie J, Adams R. Normative data for passive ankle plantarflexion-dorsiflexion flexibility. Clin Biomech 2001; 16:514-21.
15. Macedo LG, Magee DJ. Effects of age on passive range of motion of selected peripheral joints in healthy adult females. Physiother Theory Pract 2009; 25:145-64.

16. Roaas NB, Anderson GB. Normal range of motion of the hip, knee and ankle joints in male subjects, 30-40 years of age. Acta Orthop Scand 1982; 53:205-208.

17. Owalabi E, Alawale OA. Lower limb flexibility norms: some racial, gender and limb symmetrical considerations. Afr J Health Sci 1996; 3:56-9.

18. Azmi MY, Junidah R, Siti Mariam A, et al. Body Mass Index (BMI) of adults: findings of the Malaysian Adult Nutrition Survey (MANS). Malays J Nutr 2009; 15:97-119.

19. Escalante A, Lichtenstein MJ, Dhandha R, Cornell JE, Hazuda HE. Determinants of hip and knee flexion range: results from the San Antonio Longitudinal Study of Aging. Arthritis Care Res 1999; 12:8-18.

20. Koley S, Kaur N, Sandhu J. Relationship of obesity with lumbar range of motion in school going children of Amritsar, Punjab, India. IJBA 2008; 3:14.

21. Kouyoumdjian P, Coulomb R, Sanchez T, Asencio $\mathrm{G}$. Clinical valuation of hip joint rotation range of motion in adults. Orthop Traumatol Surg Res 2012; 98:17-23.

22. Ahlberg A, Moussa M, Al-Nahdi M. On geographical variations in the normal range of joint motion. Clin Orthop Relat Res 1988; 234:229-31.

23. Zelle J, Barink M, Loeffen R, De Waal Malefijt $M$, Verdonschot $N$. Thigh-calf contact force measurements in deep knee flexion. Clin Biomech 2007; 22: 821-6.

24. Gajdosik RL, Bohannon RW. Clinical measurement of range of motion. Review of goniometry emphasizing reliability and validity. Phys Ther 1987; 67:1867-72.

25. Tomoaki S, Keisuke K. Normal range of motion of joints in young Japanese people. BAMS (Kobe) 1988; 4:103-8.

26. Singh SKA. Trends of active range of motion at three important joints in school-going boys of Amritsar, Punjabi. Anthropologist 2008; 10:225-7.

27. Khalwat MRA. A prospective cross-sectional study of joint motion in healthy adult subjects. Acta Med Iran 2005; 43:151-4.

28. Reza MF, Urakami Y, Mano Y. Evaluation of a new physical exercise taken from Salat (Prayer) as a short-duration and frequent physical activity in the rehabilitation of geriatric and disabled patients. Ann Saudi Med 2002; 22:177-80.

29. Hemmerich A, Brown H, Smith S, Marthandam SS, Wyss UP. Hip, knee, and ankle kinematics of high range of motion activities of daily living. J Orthop Res 2006; 24:770-81.

30. Zhou H, Wang DM, Liu TR, Zeng XS, Wang CT. Kinematics of hip, knee, ankle of the young and elderly Chinese people during kneeling activity. J Zhejiang Univ Sci B 2012; 13:831-8.

31. Rothstein JM, Miller PJ, Roettger RF. Goniometric 